\title{
Architectures for Tinkering? Contextual Strategies towards Interoperability in E-government
}

\author{
Ralf Klischewski \\ German University in Cairo (GUC), Faculty of Management Technology, ralf.klischewski@guc.edu.eg
}

Received 05 August 2010; received in revised form 21 November 2010; accepted 22 December 2010

\begin{abstract}
Research has revealed the entanglement of e-government strategy and information infrastructure and that the control of infrastructures often remains an illusion as actual development and implementation is challenged by a constant drift. However, guidelines for public sector $\mathrm{CIO}$ how to deal with these challenges remain scarce: Are governments well advised using architectures and other conceptualizations as tools in a top-down implementation of an infrastructure based on a preset interoperability strategy? Or should governments rather develop contextual strategies that build on the understanding of the actual drift of infrastructures and employ selected architectures only as facilitators for stakeholder communication during the next phase of interoperability achievement? In view of nowadays available theoretical reflections, the case of Egypt is analyzed to examine the role of service-oriented architecture in the control and drift of the G2G infrastructure. Findings reveal that what at first seemed to be an immature vendor-driven "technology-first" approach with a clear absence of IT governance strategy, in retrospect can be considered as the appropriate choice of architecture because it has successfully impacted agendas of most local stakeholder to move into the direction of e-government interoperability. Attempting to generalize, it is suggested that strategies towards e-government interoperability should select architectures based on reflection of the specific implementation context: to embrace existing infrastructure components, to be comprehensible and acceptable by the stakeholders involved, to be suitable for designing and standardizing the next generation of component interfaces, and to provide a timelimited frame for "tinkering," i.e. allowing stakeholders to find their own way of embracing and implementing the concepts in focus.
\end{abstract}

Keywords: Interoperability, E-government, Service-oriented architecture, Information infrastructure, Strategic alignment, Egypt 


\section{Introduction}

Throughout the last years, interoperability has been in the focus of e-government practice and research. The term itself refers primarily to a technical challenge, i.e. the technical capability for e-government interoperation. Interoperation in e-government has been defined as "independent or heterogeneous information systems or their components controlled by different jurisdictions/administrations or by external partners smoothly and effectively work together in a predefined and agreed upon fashion" ([43] p. 900). To this end, governments have started initiatives and launched frameworks addressing the pressing need for interrelating existing administrative information systems in order to provide integrated services for citizens and businesses and to reduce the cost of linking these systems together.

The need for administrative information sharing was articulated long time ago (e.g. [10]). However, in spite of its obvious task-specific need, interorganizational collaboration within and among governments has also accumulated a long history of friction, conflict, and failure [43]. The actual experience of technical and organizational difficulties in egovernment collaboration has led to the rationalization of interoperability, which, in turn, has contributed much to the readiness of all actors involved to accept such kind of governance and commit to interoperability frameworks or similar instruments. The rationale behind implementing technology solutions for e-government interoperability can be summarized as a three-step argument (see also [31]):

1. Governmental agencies are in need to share information and link their administrative processes in order to fulfill their (common) strategic objectives.

2. The existing information systems and the available infrastructure do not sufficiently support such interaction.

3. In order to overcome the heterogeneity of systems and content to be shared, the intended collaboration shall be guided by dedicated integration objectives and implementation rules.

To this end, interoperability guidelines, standards, architectures and other conceptualizations have been introduced with the aim to facilitate a strategically guided top-down approach with the aim of strengthening the IT governance in the public sector. This is naturally the preferred perspective of any (governmental) $\mathrm{ClO}$, and e-government research should bring out knowledge that supports action from this perspective. However, the road of achieving the required interoperability still seems to be difficult to do for most governments. At first sight we can diagnose a lack of sharing "best practices" on how to implement interoperability step by step; but giving it a second thought, it might be questionable whether any good practice could actually be identified and/or what should be the appropriate underlying assumptions when trying to pass on recommendations. The research presented here takes up the perspective of a public $\mathrm{CIO}$, facing practical questions such as: How can a government proceed when building and upgrading its IT infrastructure towards more interoperability? What is the role of architectures and other conceptualizations in such endeavors? And how new opportunities can be seized which open up through new IT technologies and services?

Previous research by Ciborra et al. [6] has revealed that the control of corporate IT infrastructures often remains an illusion as actual development and implementation is challenged by a constant drift; and even strategic information systems should embrace "tinkering" and bottom-up development to be successful and sustainable instead of insisting on a top-down approach. If we accept the path dependency due to organizational and technical legacy as well as the impact of at last uncontrollable stakeholder activities on shaping of e-government infrastructures (and thus deployment of ICT itself becomes part of the policy-making process), then we should strive to reconsider the underlying assumptions of interoperability development strategies and provide more mature guidance how to make best use of architectures and other conceptualizations for infrastructure development: Are governments well advised using architectures and other conceptualizations as tools in a top-down implementation of an infrastructure based on a preset interoperability strategy? Or should governments rather develop contextual strategies that build on the understanding of the actual drift of infrastructures and employ selected architectures only as facilitators for stakeholder communication during the next phase of interoperability achievement?

The field of tension between both of the above perspectives will be unfolded to examine the efforts for achieving G2G interoperability in Egypt, a country which in recent years has achieved notable success in e-government [9]. Previous case studies ([31], [32]) found evidence that the strategy of the Egyptian government can be clearly characterized as a "technology-first" approach because the first step in developing an e-government interoperability approach was to decide on the statewide implementation of a service-oriented architecture (SOA); and only after several years a G2G framework is now being developed that shall tune in government agencies to use the available infrastructure for collaboration purposes. This approach did not match the interoperability development path taken by industrialized countries, therefore we had asked to what extent the Egyptian experience might indicate a model for egovernment adopters on how to do develop interoperability right from the beginning. At first, the idea was to identify good practice towards interoperability development that could and should be shared. However, in view of the theoretical controversy the case material from Egypt is revisited to analyze the role of architecture in the control and drift of the G2G infrastructure. The aim is to reflect to what extent the selected architecture enabled control of the interoperability development and how "tinkering" and incorporating the contextual issues formed the actual infrastructure. 
In this paper, the following two sections elaborate the contrasting theoretical perspectives by tracing the relevant literature. Then the research methodology is laid out, followed by the empirical account of decision-making and ongoing implementation of a service-oriented architecture as the basis for e-government interoperability in Egypt. Finally, the case of Egypt is assessed in terms of infrastructure governance and interoperability development, and possible generalizations are put forward along with pointers to future research.

\section{In Search of Mastering E-government Interoperability}

In the context of e-government many authors refer to interoperability basically as the "ability to exchange information and mutually to use the information which has been exchanged" (a 1991 definition of interoperability by the European Commission; cited from [17] p. 163). Having gained importance on the political agendas, e-government research has made some effort to gain insights on how governments manage to establish and improve interoperability among governmental institutions as well as with external partners and other peers.

The main driver for e-government interoperability is considered to be the need for interorganizational information integration (cf. [30], [39], [40]). The integration processes as such need to be studied from multi-disciplinary perspectives ([39], [43]) because organizational and technical resources and artifacts are framing and are formed by the social processes making use of these. E-government interoperability is an outcome of this dynamic interrelation, in which interoperability frameworks, standards and architecture play a major role. However, all authors concede that interoperability can only be adequately understood in view of higher-level integration concepts such as information and process integration ([30], [36]) or from the perspective of defined maturity levels of organizational interoperation [15]. After all, interoperation and information sharing rest on the participants' capacity for inter-organizational collaboration, and establishing interoperability means to set and agree on certain standards facilitating the interoperation. Such initiatives and frameworks usually address several levels including technical and organizational issues, acknowledging that interoperability in e-government can only succeed on the basis of stakeholder commitment to inter-organizational collaboration. The concept of interoperability framework has been defined, for example, as "a set of standards and guidelines that describes the way in which organizations have agreed, or should agree, to interact with each other" ([12] p. 3).

Most authors agree that interoperability and development of the IT infrastructure has gained top management attention in governments and administrations. Both issues are nowadays high on the e-government agenda, driven by the interest to improve interaction with citizens and businesses as well as reducing administrative cost. All of these approaches assume that interoperability is best to be achieved when governments are in the driving seat, defining clear strategies and pushing forward interoperability frameworks, architectures and other conceptualizations that will enable all actors involved to implement the interoperability vision in a coordinated manner. For example, Ebraim and Irani analyze that an e-government strategy is a fundamental element in modernizing the public sector and that government leaders and officials are increasingly aware of e-government's potential to improve the performance of government organizations and to provide benefits to their citizens and business partners; the authors point at the strategic importance of aligning policy and technology ([13] p. 591): "A public sector organisation planning to adopt an e-government initiative and formulate its IT strategies must evaluate its business models and select appropriate technology solutions that deliver on central government policy."

Naturally, top management and even policy makers assume that the IT infrastructure can be developed intentionally, otherwise interventions are meaningless. The underlying idea is that of strategic alignment aiming for a "strategic fit" between business and IT strategy, on the one hand, and the organizational and IT infrastructure and related processes, on the other hand [20]. This is nowadays one of the main drivers of IT governance which intends to manage all IT related assets according to strategic objectives and based on explicit structures for communication, responsibilities and decision-making [52].

Throughout the last decade a variety of conceptualizations have been introduced with the intention to support infrastructure development, to improve interoperability, and to achieve strategic alignment:

- Service-oriented architecture: the e-Government interoperability guide provided by the United Nations Development Program recommends that a service-oriented architecture (SOA) "is the best underlying paradigm with which to begin to roll out e-government services that can be used in cross-agency and crossborder situations" ([48] p. 23). SOA can be defined as a system design of loosely coupled and reusable software components called "services." These services are designed to communicate with end user applications and/or with other services, either to process data or to carry on a certain activity. SOA focuses on of the most critical issues faced by governments, which is integration of program functionality and information across organizational boundaries in a heterogeneous technology environment. Theoretically, independent services of different platforms, languages and operating systems can exchange messages with each other. To this end a highly distributable communication and integration backbone is essential and the Enterprise Service Bus was designed to provide messages transmission between different components of the SOA eliminating the need for point-to-point connectors ([11], [37], [38]). 
- Metadata (information architecture): composing complex applications at run-time through reusing services requires semantic concepts and technologies in order to enable machines to select and bind services based on an 'understanding' of the case-specific needs as well as the specific service capabilities. To this end the idea of metadata has been introduced to e-government [47], and interfaces of e-government services have been semantically enhanced by employing a web service ontology ([3], [41], [50]).

- Process patterns: one main objective of e-government interoperability is the support of administrative processes and transactions involving citizens and businesses. Domain-specific process modeling have emerged (e.g. [1]) not only for providing cross-organizational references but also for improving IT governance (e.g. through investment evaluation [2]). To ensure utmost usability, administrative process models are suggested to be moved to standardized notations (BPMN, BPEL) while making reference also to the models of data and rules involved [33].

- Enterprise architectures: aiming at comprehensive standardization to support all levels of interoperability, governments increasingly develop so-called enterprise architectures which can be viewed as a coherent set of principles, methods and models enabling comprehensive use of the IT and other resources for supporting the business objectives. In the administrative domain we find, for example, the "Governance Enterprise Architecture" [42] including a set of domain models describing the overall governance system and serving as a top-level enterprise architecture; a four-layered "framework for e-government architecture" [13]; or an extended framework to provide a reference architecture for cross-organizational interoperation [44].

The scope of the above conceptualizations obviously varies, indicating that there is not one best way towards egovernment interoperability. The UNDP guidelines [48] conclude explicitly with the message "policy, not technology, matters", calling for designing what is needed for and by the public (and not designing based on technology that is available) as well as governments' strategic framework and the vision of its leaders. However, one of the main challenges of governing IT infrastructures is that the development activities actually happening only to some extent match the action planned, and in the same line the efficacy of the conceptualizations introduced is limited. Guijarro [17] had examined policy and practice in selecting standards for e-government interoperability frameworks and found that, while open standards are being enforced throughout all frameworks, de facto implementations reveal that more often than not proprietary technologies and specifications are used. There is evidence that developing and implementing enterprise architectures in e-government comes along with significant challenges such as handling the complexity and the ability for implementation and governance ([21], [25], [27]).

If, on the one hand, conceptualizations are considered essential for building and maintaining e-government infrastructures, but, on the other hand, the implementation of concepts and the governance of the IT infrastructure cannot be fully controlled, then we need to understand more about the uncertainties of infrastructure development in order to provide more specific guidance for governmental CIOs how to cope with such uncertainties.

\section{Control or Drift? Options and Limitations of Infrastructure Development}

Research on ICT diffusion and also ICT adoption in e-government provided many accounts that implementing IT infrastructure and information systems is not as straight forward as any ClO would hope for. For example, Helbig et al. [19] report that many public sector IT leaders and managers in the U.S. are struggling with how to align the IT governance with the overall state governance: apparently no framework or strategy works perfectly and there is no "cookie cutter method" to be applied. Indeed, a wealth of publications seeks to reflect ICT adoption within a more comprehensive socio-technical framework. The extended views are concerned with the concept of infrastructure as well as with the process of how infrastructures actually emerge.

In common language, the general meaning of infrastructure usually refers to an underlying foundation or shared resources required for an activity. Infrastructures usually have a large numbers of different users, their governance is based on mutual understanding rather than on central authority, and their design and use evolve over time [26]. In relation to information technology and, in particular, for e-government purposes diverse interpretations of the term coexist, depending on the perspective applied:

- Infrastructure as a platform: a set of hardware and software products in combination with telecommunication for developing advanced (web) applications, determining degrees of freedom in business activities (e.g. [29])

- Infrastructure as a foundation: a stable structure, a common resource, a common standard for the information society (e.g. the "information superhighway" as coined by US Senator Al Gore)

- Infrastructure as a system: socio-technological systems or complex adaptive systems [27] "that emerge and evolve through the interplay of technology, users, and policy-makers" ([26] p. 233) 
- Infrastructure as a relation: it is not a "thing" but sunk into other social arrangements, institutions, or technologies, invisible and transparent in supporting the execution of tasks, operating through standardization and extension of linkages [45]

- Infrastructure as a portfolio: corporate infrastructure consisting of IT components, human IT infrastructure (people, skills etc.), shared IT services, shared applications (e.g. [51])

Infrastructure as a product, foundation, system, relation, or portfolio - none of these interpretations should be excluded when establishing an appropriate frame of reference for discussing the infrastructure for e-government. However, depending on the perspective, the options and limitations for any comprehensive IT governance to shape the information infrastructures appear in a different light.

Having studied a variety of corporate information infrastructures, Ciborra contrasts the "centrality of control" with the idea of a constant drift, asking ([5] p. 39): "What if size and complexity make the single-loop control approach impractical and ineffective, giving only the illusion of governance, for something that cannot be fully controlled?" Ciborra ([4] pp. 68f.) even unmasks strategic alignment as being "close to a truism conceptually," which in the everyday business is far from being implemented because both concepts at the end of the alignment are unstable: "Strategy ends up in 'tinkering' and the IT infrastructure tends to 'drift'." The argument even carries on to point out that the infinite shifts and deviations of infrastructure are valuable sources of innovation, as it shows that strategic information systems allowing tinkering and bottom-up evolvement are more successful to maintain competitive advantage over a longer period of time because firms end up with something that is deeply specifically rooted in the organizational culture. Reflecting his observations, Ciborra outlines a new approach towards alignment and infrastructure deployment which incorporates the dimensions of

- Care: familiarity, intimacy, and continuous commitment, articulated in perception, circumspection, and understanding processes

- Hospitality: accepting new technologies must face ambiguity, it often needs to welcome a "stranger" (something not expected or wanted)

- Cultivation: shaping technology through "interference with and support for the material that is in itself dynamic and possesses its own logic of growth, like helping a wound to heal" ([5] p. 31)

- $\quad$ Recalling the definition of Star and Ruhleder ([45], see above), Ciborra describes the internal dynamics of IT infrastructure as

- $\quad$ "many actors are involved in its establishment or development, so that it cannot be controlled by one actor;

- $\quad$ The issue of standards becomes paramount; battles of standards involve the setting-up and management of complex coalitions of actors and technologies,

- History, path dependency, unique events punctuate the development of infrastructure and have an irreversible influence on its configuration at any given moment." ([5], p. 32)

Drawing on Latour's Actor-Network Theory, the idea of alignment then can be re-conceptualized as an alliance of humans and non-humans (architectures, standards, IT systems etc.), corresponding to the "successful translation of the interest of one actor into the behavior of another actor, within a complex network of actors and intermediaries" ([5], p. 32). In view of such limited prospects for top-down control, Ciborra recommends not separating strategy from actual implementation; in fact it should emerge from the actual implementation process to incorporate deviations, surprises, and conflicts. And the more an infrastructure is 'embedded' the more its development is determined by local and global circumstances, meaning that any general advice for governance can only have limited impact, and the underlying mental models might not be appropriate. Instead of applying "'cowboy-like' managerial models based on the unilateral control strategies of humans of non-humans", Ciborra advises that "a well-run infrastructure is the outcome of a successful alliance between human and non-human actors" ([5] p. 38).

A number of researchers have provided evidence for the entanglement of technical, organizational, economic and political issues (e.g. [8] for electronic trading infrastructures). Drawing on Fountain's [14] technology enactment framework, Cordella and lannacci call for understanding the complexity of the relation between ICT and policy making; they argue that policy goals carried by technology "are enacted by public sector organizations in their daily base actions and routines so that the outcome of e-Government reforms is shaped by the e-Government policies' aims and goals, the technological characteristics shaped by these policies and the organizational practices which ultimately shape the actual outcomes of the reforms" ([7] p. 53). However, when lannacci [24] discusses the impact of his findings about the entanglement of e-government strategy and infrastructure, he provides a number of thoughtful reflections and valuable recommendations for research - but nothing for the practitioners. 
If theory emphasizes so strongly the context and path dependency of infrastructure governance, then general advice on how to implement a specific architecture or other concept seems to be of little relevance. Rather we should shift out attention to providing advice for $\mathrm{ClO}$ and project managers on how to develop contextual strategies and how to make best use of architectures for infrastructure development in their specific context. The following sections seek to unravel the case of Egypt to see how the strategic choice of service-oriented architecture has contributed to the governance of the e-government interoperability efforts.

\section{Research Methodology}

Infrastructures operate through standardization and extension of linkages, and they rely on the alignment of stakeholders and technology. To this end the role of architecture is assumed to be essential for at least (a) providing a comprehensible and (in principle) acceptable vision for the stakeholders involved, (b) embracing the installed technology and systems, (c) designing and standardizing the to-be interfaces for the establishing the linkages. From the $\mathrm{ClO}$ perspective architectures and other conceptualizations should be strategically selected with regard to the potential they are likely to unfold (pertaining to a-c) when human actors continue their path in aligning with the (new) architecture-driven technology. To this end, research architectures, frameworks and other conceptualizations are considered in a context of ideal governance (see figure 1): grounded in an analysis of the state of interoperability at a certain time $\left(\mathrm{t}_{1}\right)$, a strategy is set that envisions a future state of interoperability at a point of time $\left(\mathrm{t}_{2}\right)$ on the basis of which architectures and other conceptualizations are selected and/or determined; by enforcing these conceptualizations to align the actual steps of infrastructure development, the strategic fit is achieved and the overall transformation from state $t_{1}$ to $t_{2}$ is "under control". Knowing that this is an ideal view, the research question leading the empirical investigation is to what extent a selected architecture in fact enables control of the interoperability development and/or how "tinkering" and incorporating the contextual issues form the actual infrastructure.

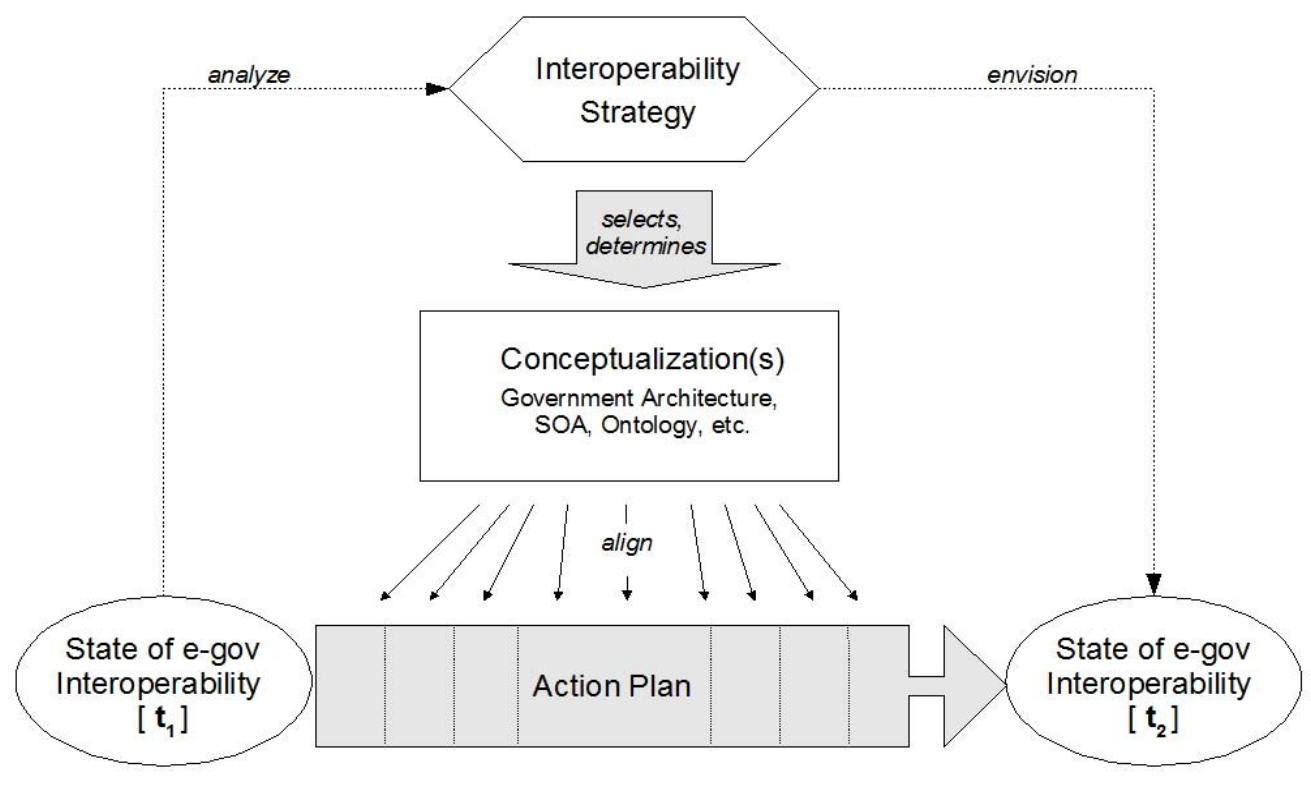

Figure 1: Ideal governance of interoperability development from the control perspective

The research method is basically a single case study approach. Data collection focuses on the origination of G2G interoperability within Egypt, a country which has made remarkable progress in the area of e-government and is ambitious to continue a "fast pace development" [9]. The case has been selected not only because of ease of access (proximity of the researcher), but because the Egyptian government has made an initial strategic decision on the statewide implementation of a service-oriented architecture (SOA) to govern its e-government interoperability efforts; and only after this has been pursued for several years, a G2G framework is now being developed that shall tune in government agencies to use the available infrastructure for collaboration purposes. This approach can be characterized as a "technology-first" approach [31] and could be attributed to the fact that Egypt (being considered as a developing country) is an e-government "follower", i.e. implementing concepts developed and practiced elsewhere, and therefore a technology adopter. Therefore, the case of Egypt may represent an appropriate strategy for countries which simply do not want to repeat the painful non-interoperability experience of their developed peers.

Initially the research questions of the case investigation have been ([31], [32]): To what extent does the Egyptian governance approach indicate a model for e-government adopters how to do develop interoperability right from the beginning? And to what extent administrations are able to follow approaches to service development and reach a successful outcome within a reasonable frame of time and resources? However, since the beginning of the case study, there had been questions if the vendor-driven adoption of service-oriented architecture was the right strategic move. Therefore, based on the above research model, the case material has been re-analyzed to find out how this 
conceptualization has impacted the agenda of the actors involved and to what extent it has contributed to the governance of the public information infrastructure. To this end the case study addresses both the strategic and practical level of the governance approach:

- $\quad$ On the strategic level it analyses how perception of interoperability problems and general interoperability objectives have translated into selecting service-oriented architecture and how the leading ministry reflects on the chosen path.

- $\quad$ On the practical level it follows up the role of the selected architecture in the interoperability development from mid of $2005\left(\mathrm{t}_{1}\right)$ up to mid of $2010\left(\mathrm{t}_{2}\right)$ in terms of set action plan, methodologies applied, implementation challenges, and actual outcome.

We have traced the development of e-government in Egypt and in particular the steps of decision making regarding the interoperability initiative based on official and/or published documents since 2004. Additionally, for three months in 2009 as well as for three months in 2010 graduate students had joined the team at the leading ministry being in charge of the G2G initiative and contributed to the G2G framework under development. Throughout this participation in-depth observations had been conducted and a variety of written material could be obtained. Information was extracted from ministry documents, informal meetings with team members, and semi-structured interviews with the program manager and program director. The author of this paper remained as observer throughout and served as a second-order interviewer in order to challenge the views of the participating data collectors.

\section{The Role of SOA in Developing G2G Interoperability in Egypt}

This section reports on the empirical findings on developing G2G interoperability in Egypt throughout the last five years. After a briefing of Egypt's short e-government history, the following subsections trace the decision making towards setting SOA as standard (strategic level), describe the ongoing effort in implementing a SOA-based G2G framework (practical level), and analyze the challenges of developing and deploying services (strategic and practical level). On the basis of this, section 6 reflects on the role of the architecture for the governance of the e-government interoperability effort.

\subsection{E-government in Egypt}

The motivations for e-government development in Egypt are manifold. Budget constraints call for reducing administrative costs; political pressure to reduce corruption levels is increasing; bureaucracy and red tape are legendary, often requiring citizens to visit government entities for a number of times to complete a certain procedure. Egypt's vision of e-government constitutes of three main principles ([35] p. 2): (a) "Citizen centric service delivery" (reflecting the "government intention to develop a one stop shop e-services approach focused at citizen's needs", (b) "Community participation" (meaning that "citizens' demands are constantly being analyzed and reflected, and private/public sector companies are active participants in project's implementation and management"), and (c) "Efficient allocation of government resources" (i.e. "productivity, cost reduction, and efficient allocation of resources are among the major expected outcomes from project implementation").

The leading role in Egypt's e-government program is held by the Ministry of State for Administrative Development (MSAD) which was established in 1976 with the aim of enhancing the efficiency of the administrative system while modernizing public services. MSAD took over the lead in 2004 from the Ministry of Communication and Information Technology (MCIT) which was established in 1999 with the aim of developing and enhancing telecommunication and overall ICT infrastructure in Egypt and which had initiated the e-government development program (note: the program director back then is now minister of MSAD).

One of the most obvious milestones of e-government in Egypt is the "Bawaba" portal (Site 1). It was launched in 2002, aiming at the fast and efficient delivery of information and services to citizens and businesses, intended to implement a one-stop shop solution. However, eight years after its inception the portal provides access to a wealth of information but for most administrative services it still lacks the possibility to conduct end-to-end transactions.

In 2004 MSAD has set new strategies and goals for the development and modernization government, and for its implementation it has currently defined four programs (Site 2):

- Institutional Development: aiming to develop plans, policies, laws and modern management structures, to adjust the salary and incentive systems, to enhance the work environment, and to develop human resources

- Governmental Services Development: aiming to provide citizens and investors with services, throughout the country, in an efficient, effective and convenient manner 
- Enterprise Resource Planning (ERP): aiming to enhance the governmental work process, to reduce government spending, and to automate public bodies through the usage of information and communication technologies

- Establishing and Integrating National Databases: aiming to establish an integrated national database, where government entities and institutions can efficient and safely exchange data

The efforts to reach out for more interoperability are mainly driven through the Service Development program, but the other programs are benefiting from established interoperability and at the same time frame the activities of its continuous enhancement.

\subsection{SOA for G2G in Egypt}

After successfully creating an e-government portal, MSAD was ready to begin focusing on other sectors of egovernment development. In 2005 a multinational IT vendor was requested to share its expertise in addressing the following priorities as specified by MSAD (the following quotes as well as other material in this section are extracted from a confidential report of the IT vendor delivered to MSAD in October 2005; the researchers were granted access to this and other internal documents):

- $\quad$ Provide quality services to citizens of Egypt

- Increase the number of services available to citizens through the e-government portal

- Improve the efficiency of administrative workflows and systems within the government

- $\quad$ Provide the government with improved data about the population for decision making purposes

According to MSAD and the IT vendor such aims can best be achieved through the integration and the aligning of the various governmental entities and that has indeed become the objective of the new initiative. According to the IT vendor it would be in MSAD's best interest to adopt SOA technology in order to enable such integration and interoperation.

In September 2005, a "project definition workshop" was conducted under the directive of MSAD's e-government program director in which seven representatives from the IT vendor met with another seven members of MSAD for in order to "evaluate several government areas within MSAD for suitability to demonstrate the value of a Service Oriented Architecture, and lay the foundation for a broader SOA based IT infrastructure rollout." With an a priori understanding about the need to align and integrate entities using SOA technology, the IT vendor performed an investigation about the government IT infrastructure existing at the time and in particular the environment in which the Pension Application and Family Card program (applications that enable citizens to request pension pay or family support) integrates with the e-government portal. The investigation assessed the existing IT infrastructure provided by multiple vendors as well as the government's human capital and business process workflow environment.

The workshop report points out the benefits of SOA for MSAD as follows: "The use of a SOA will enable the integration of common services into the operating infrastructure of both new and existing MSAD business initiatives. The use of common services can help enable the rapid instantiation of new business initiatives, improve the ability to monitor and manage activities across MSAD business initiatives, reduce operating costs and business risk through automation and simplification of business processes, and consolidate specialized IT and business skills. A Services Oriented Architecture will allow common processes to be more easily streamlined across the MSAD business initiatives, while both accommodating unique needs of each initiative as well as an evolution of the supporting infrastructure of each initiative from the existing state to one that capitalizes on the ability to share processes and resources." The workshop investigated the readiness of the Egyptian government towards SOA adoption, and also provided a vision as to which direction MSAD should follow in order to begin SOA adoption and operation. The IT vendor proposed a phased SOA adoption road map including implementation of a pilot prototype, establishment of a SOA Center of excellence (COE), and implementation of common business processes (as well as possible exceptions)

Based on the proposed road map a prototype pilot project was initiated late 2005. The pilot aimed at (1) simplification and utilization of SOA technology to improve the efficiency of a selected governmental process (which was the process of registering a new employee for pension at the Social Insurance Organization, SIO), (2) allowing the governmental entities involved in employee registration at SIO to be able to exchange information required to complete the registration workflow (the three entities to be "integrated" are the Civil State Office, CSO, the Income Tax Authority, ITA, and the SIO), (3) identification of the technical specifications and the architecture requirements for the Enterprise Service Bus (ESB) as well as establishing a connection between both the ESB and the government portal allowing web services deployed on the ESB to support the portal's one-stop shop applications. The prototyping project came to an end in 2007 and was considered to be great success because (according to a 
vendor presentation to MSAD in 2006) it contributed to, amongst others, improved process execution time and satisfaction for citizens, increased productivity of government staff, and reduced number of improperly rejected applications. MSAD was satisfied with the results of the pilot as it met the ministry's objectives of creating a loosely coupled architecture that allows the various governmental entities to exchange information and data: (a) full automation of the process of registering an employee for pension subscription at SIO was achieved, (b) connections between the three governmental agencies (CSO, SIO and ITA) had been established, (c) suitable technical specifications and architecture for the ESB hub have been identified, and (d) an infrastructure was created that allows the ESB to connect with the Egyptian government portal (through a virtual private network).

However, in spite of the technical readiness, an actual connection of the ESB with the government service portal had never been established nor tested during the pilot project. This testing failed because administrative service providers were not willing to have their services accessed by the citizens directly through the portal. Nevertheless, MSAD was satisfied with just ensuring that on the technical level a connection can be made. Furthermore, the pilot allowed MSAD personnel to overcome the fear of adopting SOA technology as they became more familiar with its concepts and potential benefits as it had led to several improvements and capacity building.

Summing up, in this phase the project definition workshop provided a rationale to the causes that should drive MSAD to adopt SOA technology as well as assessing the readiness of MSAD towards adopting such a technology. The decision makers had been provided with an analysis of the current state as well as with a vision for the future state of interoperability. In addition, the prototype provided reassurance that SOA is the right technology path to follow and that it will create an infrastructure that suits best the government's needs.

\subsection{G2G Framework Development}

The "Bawaba" portal was introduced with the vision to implement a one-stop shop solution. However, the obvious incapability of conducting end-to-end transactions is permanently creating a demand for appropriate backend solutions that enable data exchange and process integration between the various governmental agencies involved on a vertical and horizontal (intra and inter agency) level. With this interoperability need in mind, and in view of developing and integrating national databases, a project was initiated in 2005 with aim of enabling various agencies to share and exchange information and services, and eventually orchestrating joint administrative processes. This effort was then coined as the development of G2G framework, with the objectives shifting over time more to enabling ministry interoperation than connecting to "Al Bawaba" services.

Once being convinced about pushing SOA as the standard for interoperability solutions, MSAD was encouraged to pursue implementing a nationwide SOA that enables information integration between all governmental entities and another. However, it was not until January 2009 that implementation of the actual project began: it was now named "Government to Government Services Bus" aiming to provide a common back-bone layer based on which the governmental entities systems can be integrated. The high-level objectives mentioned for this project are increasing services outreach to all beneficiaries (including government), timely and efficient services delivery, as well as more services productivity, quality, and performance. The IT vendor also listed a number of direct and indirect business values which could turn out to be the result if certain prerequisites with an agile technical foundation for the G2G services integration can be achieved, namely data consistency (i.e. each data element will be the responsibility of a specific entity) and processes simplification (suitable for one-stop services). As the process of implementing a nationwide SOA requires extensive efforts, it has been segmented to four phases:

Phase zero (ended in April 2009): The first two months were allocated to requirements gathering as the need to make additional adjustments in the exact requirements of the SOA environment were essential in order to further adapt it to an actual working (production) environment.

Phase one (planned until December 2010): The focus is on addressing the needs of the governmental entities for the informational services, and selecting the best model for the information sharing for these entities. This phase is considered to be the most critical as it starts with the basic atomic services addressing the core business needs across the governmental entities. Priority is given to installing the necessary components that allow SOA governing, monitoring, management, routing and back up. Then, towards the end of the phase, it is expected that ten informational atomic web services will be deployed in addition to the establishment of a G2G portal available only for participating governmental entities (and not for citizens).

Phase two: The main focus here shall be channeled towards the development and deployment of composite and transactional services that enable integration by facilitating the possibility of updating data on certain information systems.

Phase three: This phase is planned to be a consolidation of the services implemented in phases one and two into complete end-to-end business processes.

"Phase zero" came to an end as planned where the ESB's technical specifications and architecture documents had been completed. The main deliverables of phase zero was the provision of completed requirements document that determines the exact specifications of ESB, the specifications that service providers as well as service consumers 
are expected to comply to, and finally a fully detailed architecture document. The final draft has segmented requirements to three levels of priority (high, medium and low). Additional adjustments involved extra security, more enhanced routing, and better service monitoring and life cycle management. At the time of writing the project is going through the second phase ("phase 1"). The ESB is technically up and running and some atomic web services have been developed such as the national ID validation and tax information validation.

As decisions for technology concepts and products have been made early in the process and the technical infrastructure starts to reach out, MSAD and other government entities now proceed to embracing these technologies within a more mature framework of organizational readiness and IT governance. For example, in early 2010 MSAD has identified the roles and stakeholders pinpointing the responsibilities and the need for coordination when developing services supporting G2G interoperation in Egypt (see figure 2).

G2G Project

Stakeholders Chart

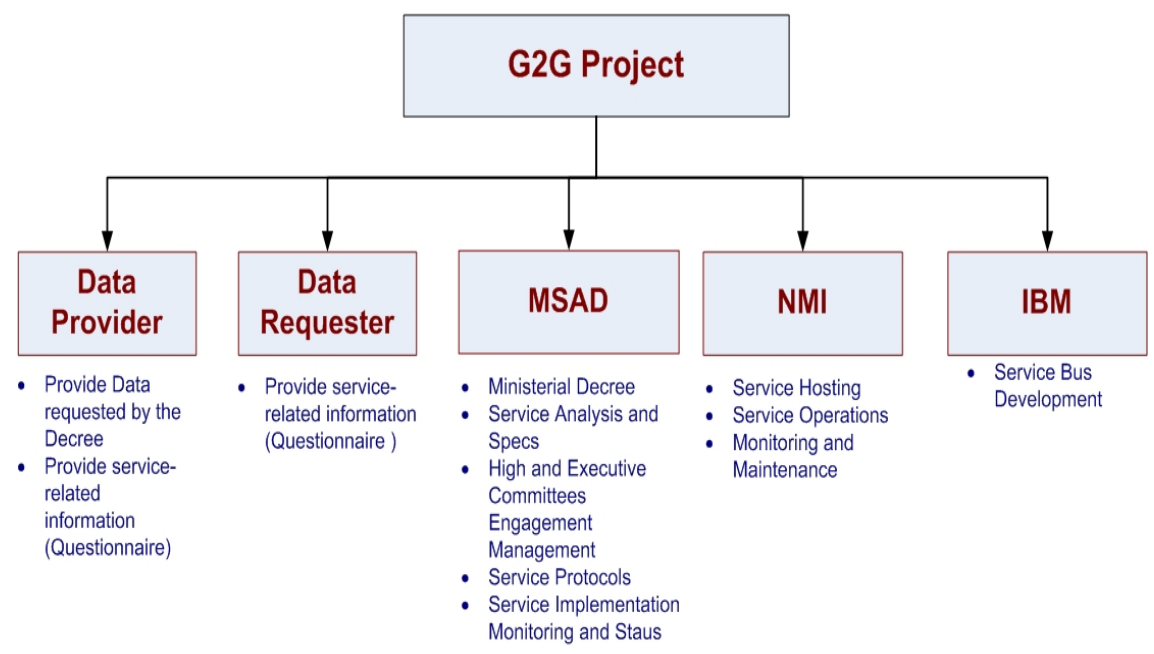

Figure 2: G2G project stakeholder chart (source: MSAD)

The IT vendor had previously highlighted that a SOA center of excellence is crucial to the success, mainly through establishing a SOA governance model, establishing policies and producing methodologies and approaches for performance monitoring. Now MSAD is responsible for executing the e-government services automation plan by studying the services and providing analysis and design. There are two committees in MSAD, the "high committee", which selects the services to be developed and selects executives to work on them, and the "executive committee", which coordinates the service development. The MSAD is also responsible for coordinating the multi-party agreements for service provision and monitoring the service implementation. The National Management Institute (NMI) is responsible for technical communication of the services, i.e. for running the ESB (developed by the company IBM) and monitoring service operations. Service requesters (depicted as "data requester") are government entities on various levels providing service requirements for development, and service providers (alias "data provider") also provide service specification as well as the actual data requested.

For developing G2G services MSAD has defined a general process to interrelate the contributions of the stakeholders involved (see Figure 3):

- $\quad$ The administrative service at the front-end is studied in order to identify the required back-end services that need to be implemented (if not available already).

- Gathering the stakeholders' requirements is based on a standardized questionnaire for service requesters as well as service providers: the questionnaire templates mainly focus on aspects of the current work practices and the feasibility of computerization but only marginally on the data to be shared.

- Having shared the requirements (translated into features) among requester and provider and, developers are asked to provide the service specifications, based on XML guidelines.

- MSAD mediates a template-based multi-party agreement and commitment on service operations ("service protocol").

- Finally a time plan ("work plan") for the service implementation and operations is created and shared with the parties involved. 


\section{G2G Context Diagram}

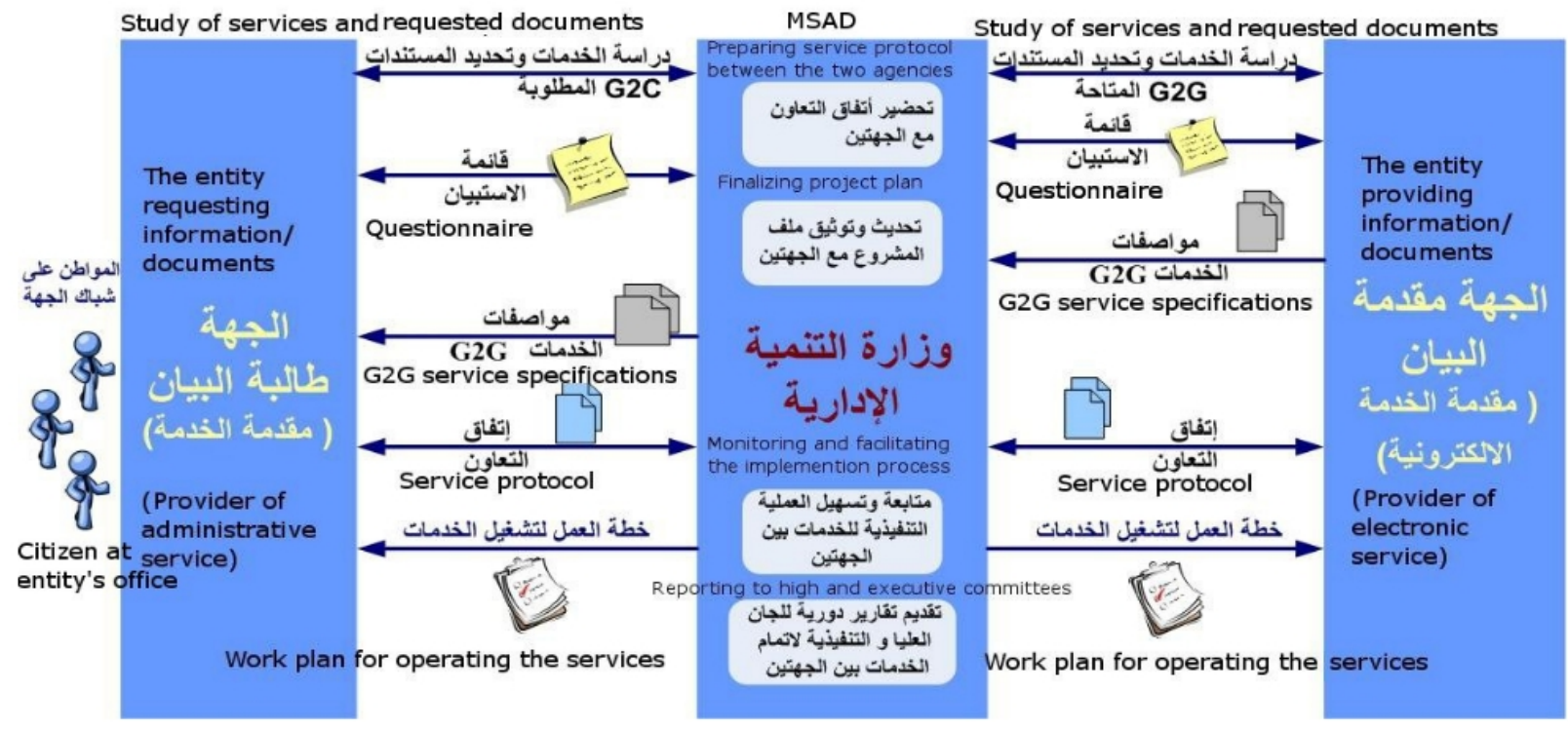

Figure 3: G2G context diagram (source: MSAD, translation added, original in Arabic with only the title in English)

Furthermore MSAD [34] has actually published an initial document addressing an Enterprise Architecture Framework for the Egyptian Government. However, this document did not unfold any impact yet. In spite of explicit high-level strategy for interoperability development, up to today the approach primarily focuses on technology issues. In April 2010 the prime minister of Egypt supported further by issuing the decree no. 856 concerning the commitment of ministries, government bodies and affiliated authorities to allow and exchange data between them in accordance to the national plan on data exchange and integration. Currently an "Information Exchange Law" is under preparation in order to force the governmental entities more explicitly into cooperation and mutually sharing important information for providing efficient services for the citizens.

\subsection{Service Development and Implementation}

In practice the development and deployment of G2G services still remains a cumbersome and thorny task, and managing the related processes across the stakeholders has not yet reached a degree of maturity which would ensure the success of the G2G project. Among the most recurring challenges to be addressed in service development are issues of service scoping, service interface granularity, choreography, interaction modes, and semantics [32]. The management at MSAD is well aware of the need for a methodology-driven approach to providing e-government services to citizen as well as for ensuring the readiness of other stakeholders to contribute to this approach. So far, service scoping is based on a requirement analysis which is framed by a preset schedule of egovernment service implementation. In the original plan of the e-government program, MSAD conducted a study on more than 790 services offered by different governmental agencies. These services were prioritized according to frequency of requests and number of governmental documents required. On the basis of this two implementation plans were created: one is concerned with the most commonly asked documents (or information entities) requested from citizens or other agencies, respectively, identifying the kind of documents and the specific data requested (e.g. the national identity card for complete name and birth date). And the other plan is a selection of a small number of "atomic" services to be developed in "phase one" (see above), including which agencies are the administrative service provider and what documents are requested from other agencies.

However, the requirement analysis so far is rather rudimentary and, for example, not requesting details of data specification and information quality. In fact, beyond ensuring consistency of naming in message headers and bodies, issues of semantic interoperability seem to not yet have appeared on the agenda - which is expected to change when services are productive and being reused, and the overall complexity increases. Currently, MSAD is deciding about the reuse and combination of existing services to let them contribute to high-level services or processes, thus determining service granularity, choreography and interaction modes. But the business logic is kept simple, and for the majority of the front-end services the aim is to map each to one or two back-end services. So far there is no explicit approach in sight that would allow for a systematic decomposition based on business process analysis and evaluation of the service portfolio.

Since MSAD has the overall responsibility for developing administrative services, it takes the lead in analyzing and designing the web services. Inside MSAD the above mentioned committees select the services to be developed and coordinate the overall development process, as the program director states: "Being the regulator of the service development process, we are responsible for the overall process management; and since we see the whole picture 
and get requirements from all parties, we translate the these requirements into features and hand in these features to the developers."

The activities in between gathering the requirements and implementing the web service, the project manager described as follows: "First, we study the requirements and decide on the technical specifications and web services that need to be developed. Second, we design each web service in XML. Third, we explain to each entity involved in the project what their web service does and how they should deal with it. Fourth, each entity implements the web service at their side. Finally, we configure the web services on the ESB." So far, the jump from the requirements to the XML-based interface is not supported by any explicit methodology and/or conceptualizations. And while MSAD had been involved in coding some initial services, the objective is to let the developers on the side of service providers and requesters do the programming work. As far as technical service development and implementation is concerned, MSAD plans to continue relying on outsourcing partners ("we prefer to let the businesses in our country work"). This is certainly in line with MSAD's role definition which is "to regulate, and not to implement."

In conclusion, the development of services, aiming to implement SOA-based G2G interoperability in Egypt, is governed by some methodology, but the level of detail in analyzing and designing service interaction is not sufficient to capture and share all requirements and transform them predictably into running web services. While the current approach might be adequate for the start-up phase, it is foreseeable that mastering the complexity of a statewide egovernment environment needs further enhancements in terms of methodology, architecture and/or other conceptualizations.

\section{Successfully Governed?}

The government of Egypt has decided early on to ground its interoperability efforts on the implementation of a service-oriented architecture. This decision had been strategic in the sense that choosing an adequate concept for the technical infrastructure was expected to facilitate all future e-government interoperation and integration efforts. And only after this has been pursued for several years, a G2G framework is now being developed that shall tune in government agencies to use the available infrastructure for collaboration purposes. Note that many of the agencies still have no experience of providing electronic services and thus lack the awareness of interoperability problems from their own perspective.

Seeking to assess the case of Egypt, the question is if the strategic decision for SOA and its subsequent implementation efforts can be considered a "successful" case of governing the development of e-government interoperability. The following subsections summarize the story from the different theoretical standpoints unfolded above, i.e. interpreting governance primarily as control or as a continuous alignment of human and non-human actors.

\subsection{Agenda Setting Through "Technology First"}

The classic view of IT governance and strategic alignment puts the business strategy in the driving seat to lead the IT strategy and subsequently the IT infrastructure. In the case of Egypt, several differences of the implementation compared to an "expected" organizationally driven approach are obvious: the leading ministry teamed up with a major IT vendor to decide early on implementing SOA-based technology solutions, while at the same time the organizational requirements remained vague and stakeholders on the demand-side were neither involved nor ready to participate in the interoperability effort. Throughout the last years the leading ministry heavily invested in technology products and consultancy. However, recalling the objectives stated in 2005 (providing quality services to citizens, increasing the number of services available to citizens through the e-government portal, improving the efficiency of administrative workflows and systems, providing the government with improved data about the population for decision making purposes), none of these have been accomplished because of SOA implementation. No control of administrative goal achievements has been exerted (only for prototype), and a cost-benefit analysis is not in sight. Even the success of prototype implementation, which led to an automation of the process of registering an employee for pension subscription, could have easily been achieved also without SOA.

Recalling that infrastructures operate through standardization and extension of linkages, the role of the selected architecture has successfully provided a comprehensible and largely acceptable vision for the stakeholders involved, embracing the already installed technology and systems. However, architecture's role in designing and standardizing the interfaces for interoperability has been limited. Some of the limitations and challenges for SOA-based G2G are technically inherent and apply also to the case of Egypt [31]: data accuracy and meta models are key enablers which do not come through SOA but their absence is a major inhibitor; SOA is not an efficient backbone for providing bulk data needed for political decision support; vendor-driven SOA introduction increases the risk of technology lock-in. Other SOA-related challenges have not yet been addressed sufficiently, for example it lacks an effective legal framework (prerequisite for establishing an integrated management structure and ensuring the conditions and sustainability of collaboration among ministries, governorates, municipalities etc.) as well as the organizational readiness to address semantic and organizational issues of G2G which are key to reaping benefits of early SOA technology investments. 
The government has made considerable effort in upgrading the IT governance, but the scope of the intended regulation still seems to be vague. On the one hand, the commitment to a methodology-driven approach to service development is reiterated; the main reasons mentioned are the objectives of service consistency, reuse and interoperability. On the other hand, the methodology currently put forward does not sufficiently address the many challenges of service development, but the ministry apparently does not perceive this as a bottleneck in aligning multiple parties to the development of G2G services.

Summing up, the technology-first approach has established facts early on (e.g. prototypes) and framed the discourse of cooperation even before collaborating partners developed their own strategies. In case of SOA for example, other governmental entities are being addressed as service providers and/or service consumers right from the start; it has influenced their mindset of participation and of conducting their own requirement analysis. And the supply-side stakeholders (in our case: MSAD and the IT vendor) have become more committed to a persistent strategy the more resources are actually spent on the selected technology path. From the control perspective, the technology-first approach of choosing SOA, before introducing the practice of strategic alignment and the instruments of IT governance, is slowly making its way, but it is certainly not a short-cut for an e-government adopter. The strategic enforcement of the architecture could not substitute or speed-up the processes of organizational learning and establishing cooperation. Compared to its ambitions, Egypt now faces the risk of major delays because organizational issue are not addressed in timely and sufficient manner, at least, it falls short in controlling and finetuning on-the-ground activities and fails to deliver the (short) gains for which the decision makers had hoped for.

\subsection{Contextualization: Aligning Stakeholders, Architecture and Technology}

If not from the control perspective, has Egypt succeeded in improving governance of the public information infrastructure through contextualizing the chosen architecture? Focusing more closely on the actors involved, we can see that the motivation for setting up SOA upfront had its context-specific rationale. First, the e-government program and the top policy makers originally came out of the MCIT which has a successful record of significantly improving the country's ICT infrastructure in a few years; here the technology-first approach has led to widespread internet connectivity and impressive take-up rates (although not for e-government applications). Second, the ministry's a priori confidence in a technology-first approach met with the IT vendor interest in seizing business opportunities, thus constantly re-emphasizing the strategy and reassuring each other. Third, the reluctance or even unwillingness of other stakeholders (e.g. other ministries) to seriously engage in cooperation keeps discouraging any effort to solve the organizational issues at stake. Forth, when consensus finding and cooperation remains difficult, establishing facts is a viable approach; once the technical infrastructure is ready it is reasonable to assume that further application development and organizational take-up will become much easier. And finally, the ministry seeks to continue its success story in "fast pace" e-government development: the opportunity to jump ahead shall not be missed even though there might be organizational implementation obstacles.

Reviewing the strategy of G2G interoperability so far, MSAD is confident that opting for SOA was the right decision. For example the program director notes that SOA has been an effective facilitator in convincing the other entities to participate in G2G projects because it ensured existing data ownership and privacy ("we're not dealing with databases, we're dealing with web services") as well as the freedom of the participating entities to keep their IT platforms and vendors. Apparently the ministry uses the architecture to implement a divide-and-conquer approach, for example, the 'freedom' even goes as far as the project leader lets the participating entities develop the services according to their liking, without enforcing detailed methodologies and information architectures.

The SOA prototype project initially embraced the "Al Bawaba," but the interoperability objective was not reached at that time, leaving the portal as a permanent and public caller for interoperability solutions. When the ministry realized that the SOA approach alone did not convince everyone and that a number of potential service providers remain reluctant to cooperate (regarding e.g. granting access to internal applications and providing resources for development), the missing alignment is now enforced by law to drive reluctant stakeholders into the collaborative environment.

Although quick gains have not been accomplished, the ministry is quite persistent in its leading role and has spent much effort on following the principles of care, hospitality, and cultivation (see section 3), and Egypt still has all the options to reach the set objectives. In short, choosing and implementing the "right" architecture upfront had a positive impact on streamlining the organizational discourse, on aligning stakeholders and technology, and on following a consistent e-government interoperability strategy. Over the years, much organizational learning has been accomplished on the side of MSAD, especially regarding infrastructure management. However, SOA cannot be the guiding vision for solving all problems coming up, and MSAD would be well advised in promoting also other conceptualizations which set the agenda for the next couple of years.

\section{Conclusion}

This paper started out asking from the $\mathrm{ClO}$ perspective how governments could proceed when building and upgrading their IT infrastructures towards more interoperability and seeking to benefit from new IT technologies and services: Are governments well advised using architectures and other conceptualizations as tools in a top-down 
implementation of an infrastructure based on a preset interoperability strategy? Or should governments rather develop contextual strategies that build on the understanding of the actual drift of infrastructures and employ selected architectures only as facilitators for stakeholder communication during the next phase of interoperability achievement?

In the case of Egypt it is a fact that the administrative entities are still far from enjoying wide-spread e-government interoperability. This could be attributed to the lack (or failure) of the IT governance because the management of the interoperability efforts has not exerted sufficient control on the SOA-guided activities that were intended to bring out a new state of interoperability. For example, the implementation of technology solutions for e-government interoperability was not driven by a collective needs analysis, which we usually expect as a rational approach to IT governance. However, it can also be argued that, in its situation as a technology adopter, Egypt is actually on the right path: because demand-side stakeholders are lacking e-government experience and therefore cannot initially contribute to the organizational interoperability, nor reliably follow a preset methodology, the only rational way to proceed is deciding on and implementing a well-recommended technology path (such as SOA), align other stakeholders step-by-step as the technology implementation proceeds, and seek for ad hoc solutions as problems unfold on the way.

This research has no intention to advocate a so-called technology-first approach; it is just concerned with the way of choosing and promoting an architecture while striving for governance of the public information infrastructure. In this respect, we might be well advised to reset our expectations regarding the rationale driving the implementation of egovernment interoperability. Variations in e-government histories and track records, combined with specific differences in political structure and culture, might lead to the insight that some of our assumed-to-be-reasonable approaches cannot be used as expected in other places. For example, in the case of Egypt the leading ministry realized that in the given context of administrative development the options for control are very limited; it used its own governance potential as far as possible to select the architecture and invest in infrastructure technology, knowing well that, in contention with the technology provided, the stakeholders involved eventually will have to align with the (new) architecture-driven technology and will find their own way to shape up as a service provider and/or consumer. The case study confirms that a SOA-based approach to interoperability has a lot of potential, but needs to be adequately adjusted and enforced as a tool for the development of administrative interoperation. From other experience we know that building up interoperability between governmental agencies is an intricate effort which takes years to accomplish, especially between agencies largely inexperienced in e-government provision. Within the given context, Egypt has exploited the SOA potential to some extent, but it has been slow in following up and addressing issues outside the reach of any SOA-based solution.

Finally, despite a single case study being very limited in its explanatory power, what is the general advice for CIOs to put forward? Even without assuming full control over the infrastructure development and without substantial organizational readiness of the stakeholder involved, architectures and other conceptualizations can be used as effective tools for implementation when strategically selected according to their potential pertaining to standardization and extension of linkages in a given context. In the case of Egypt the most basic interoperability architecture was selected for loosely coupling existing functionality; but the same principle can apply to higher levels of information and process management (e.g. ontologies, process models, enterprise architectures) as well as technical levels of communication (e.g. protocol stack).

As administrative settings are mostly characterized by multiple stakeholders with more or less independent agendas, top-down approaches towards governing public information infrastructure are always significantly limited. Therefore contextual strategies towards implementing e-government interoperability are expected to play a greater role than control-seeking strategies, and this extends also to the selection, promotion and implementation of architectures. Tentatively extrapolating the Egyptian experience, it can be summarized that architectures for interoperability should be selected based on reflection of the specific e-government context, embrace existing infrastructure components, be comprehensible and acceptable by the stakeholders involved, be suitable for designing and standardizing the next generation of component interfaces, and provide a time-limited frame for "tinkering," i.e. for allowing stakeholders to find their own way of embracing and implementing the concepts in focus. This approach to "gardening" the grass-root efforts of alignment is likely to bring out a more sustainable state of interoperability that serves the needs of infrastructure users. However, for CIOs to be more practical in following this approach, future research needs to analyze the impact of various architectures on infrastructure governance and alignment processes while taking into account the specific circumstances of the interoperability development.

\section{Acknowledgments}

The support of the Egyptian Ministry of State for Administrative Development is gratefully acknowledged for allowing us a close-up on their infrastructure development activities. 


\section{Websites List}

Site 1: Egyptian Government Services Portal http://www.egypt.gov.eg

Site 2: Ministry of State for Administrative Development $\rightarrow$ About MSAD $\rightarrow$ Programs http://www.msad.gov.eg/About\%20MSAD/Programs/

\section{References}

[1] J. Becker, D. Pfeiffer, and M. Räckers, Domain Specific Process Modelling in Public Administrations - The PICTURE-Approach, in Proceedings EGOV 2007 (Wimmer, M.A., Scholl, J., Grönlund, Å., Eds.), LNCS, vol. 4656, Springer, Heidelberg, 2007, pp. 68-79.

[2] J. Becker, P. Bergener, S. Kleist, D. Pfeiffer and M. Räckers, Business Process Model-based Evaluation of ICT Investments in Public Administrations, Proceedings of $14^{\text {th }}$ Americas Conference on Information Systems, Toronto, Canada, 2008.

[3] P. Bednar, K. Furdik, M. Kleimann, R. Klischewski, M. Skokan and S. Ukena, Semantic Integration of e-Government Services in Schleswig-Holstein, Lecture Notes in Computer Science, vol. 5184, pp. 315-327, September 2008.

[4] C. Ciborra, De profundis? Deconstructing the concept of strategic alignment, Scandinavian Journal of Information Systems, vol. 9, no. 1, pp. 67-82, 1997.

[5] C. Ciborra, A critical review of the literature on the management of corporate information infrastructure, in From Control to Drift. The Dynamics of Corporate Information Infrastructures (C. Ciborra, K. Braa, A. Cordella, B. Dahlbom, A. Failla, O. Hanseth, V. Hepsø, J. Ljungberg, E. Monteiro, Eds.), Oxford University Press, 2000, pp. 15-40.

[6] C. Ciborra, K. Braa, A. Cordella, B. Dahlbom, A. Failla, O. Hanseth, V. Hepsø, J. Ljungberg, E. Monteiro, From Control to Drift. The Dynamics of Corporate Information Infrastructures, Oxford University Press, 2000.

[7] A. Cordellaa and F. Iannacci, Information systems in the public sector: The e-Government enactment framework, Journal of Strategic Information Systems, vol. 19, no. 1, pp. 52-66, March 2010.

[8] J. Damsgaard and K. Lyytinen, Building Electronic Trading Infrastructures: A Public or Private Responsibility?, Journal of Organizational Computing and Electronic Commerce, vol. 11, no. 2, pp. 131-151, 2001.

[9] A. M. Darwish, Egypt: from e-government to e-governance - the road to fast pace development. Proceedings ICEGOV 2008, ACM Press, 2008, pp. 1-3.

[10] S. S. Dawes, Interagency Information Sharing: Expected Benefits, Manageable Risks, Journal of Policy Analysis and Management, vol. 15, pp. 377-394, 1996.

[11] K. Declercq, A. Vincent, T. De Backer, and H. Loterie, Study on potential reuse of system components, IDABC Program, in EIIS, Final report study II, Version 1.1. European Communities, 2009.

[12] European Communities. (November, 2004) European Interoperability Framework for Pan-European EGovernment Services, Office for Official Publications of the EC, Luxembourg. [Online]. Available: http://xml.coverpages.org/IDA-EIF-Final10.pdf

[13] Z. Ebrahim and Z. Irani, E-government adoption: architecture and barriers, Business Process Management Journal, vol. 11, no. 5, pp. 589-611, 2005.

[14] J. E. Fountain, Building the Virtual State: Information Technology and Institutional Change, Brookings Institution Press, Washington, DC, 2001.

[15] P. Gottschalk, Maturity levels for interoperability in digital government, Government Information Quarterly, vol. 26, no. 1, pp. 75-81, 2009.

[16] S. Gregor, D. Hart, and N. Martin, Enterprise architectures: enablers of business strategy and IS/IT alignment in government, Information Technology \& People, vol. 20, no. 2, pp. 96-120, 2007.

[17] L. Guijarro, Policy and Practice in Standards Selection for E-Government Interoperability Frameworks, in Proceedings of the 4th International Conference on Electronic Government, Copenhagen, 2005, pp. 163-173.

[18] L. Guijarro, Interoperability frameworks and enterprise architectures in e-government initiatives in Europe and the United States, Government Information Quarterly, vol. 24, no. 1, pp. 89-101, 2007.

[19] N. Helbig, J. Hrdinová, and D. Canestraro, Enterprise IT governance at the state level: An emerging picture, in Proceedings of the 10th International Digital Government Research Conference, Puebla, 2009, pp. 172-179.

[20] J. C. Henderson and N. Venkatraman, Strategic alignment: leveraging information technology for transforming organizations, IBM Systems Journal archive, vol. 32, no. 1, pp. 4-16, 1993.

[21] K. Hjort-Madsen, Enterprise Architecture Implementation and Management: A Case Study on Interoperability, Proceedings of the $39^{\text {th }}$ Annual Hawaii International Conference on System Sciences, IEEE, 2006.

[22] K. Hjort-Madsen and J. Pries-Heje, Enterprise Architecture in Government: Fad or Future? Proceedings of the $42^{\text {nd }}$ Annual Hawaii International Conference on System Sciences, IEEE, 2009.

[23] L. L. Humes and N. Reinhard, The Influence of Power in the Development of an Information Infrastructure, in Proceedings of EGOV 2008, Turin, Italy, 2008, pp. 37-48.

[24] F. Iannacci, When is an information infrastructure? Investigating the emergence of public sector information infrastructures, European Journal of Information Systems, vol. 19, no. 1, pp. 35-48, 2010. 
[25] H. Isomäki and K. Liimatainen, Challenges of Government Enterprise Architecture Work - Stakeholders' Views, in Proceedings EGOV 2008 (M.A. Wimmer, H.J. Scholl, and E. Ferro, Eds.), Lecture Notes in Computer Science, vol. 5184, 2008, pp. 364-374.

[26] M. Janssen, S.A. Chun, and R. Gil-Garcia, Building the next generation of digital government infrastructures, Government Information Quarterly, vol. 26, no. 2, pp. 233-237, 2009.

[27] M. Janssen and G. Kuk, A Complex Adaptive System Perspective of Enterprise Architecture in Electronic Government, Proceedings of the $39^{\text {th }}$ Hawaii International Conference on System Sciences, Hawaii, IEEE, 2006, p. 71.

[28] M. Janssen and R. Wagenaar, Enterprise Architectures as Knowledge Sharing Instrument: Concepts and Challenges, in Knowledge Transfer for eGovernment: Seeking Better eGovernment Solutions (R. Traunmüller, Ed.), Trauner Verlag, Linz, Austria, 2006 p. 82-91.

[29] P. Keen, Shaping the Future: Business Design Through Information Technology, Harvard Business School Press, Massachussetts, 1991.

[30] R. Klischewski, Information integration or process integration: How to achieve interoperability in administration. Proceedings EGOV 2004, Springer LNCS 3183, Berlin, 2004, pp. 57-65.

[31] R. Klischewski and R. Abubakr, Can e-Government Adopters Benefit from a Technology-First Approach? The Case of Egypt Embarking on Service-Oriented Architecture, Proceedings HICSS-43, IEEE, 2010.

[32] R. Klischewski and E. Askar, Success Factors of Developing G2G Services: the Case of Egypt, Proceedings of the $4^{\text {th }}$ International Conference on Theory and Practice of Electronic Governance (ICEGOV 2010), ACM Press, 2010, pp. 152-160.

[33] F. Lampathaki, S. Koussouris, G. Gionis, Y. Charalabidis, and D. Askounis, Cross-Dimensional Modelling Patterns to Empower Pan-European Business to Government Services Interoperability, in On the Move to Meaningful Internet Systems: OTM 2009 Workshops, Berlin, 2009, pp. 152-161.

[34] Ministry of State Administrative Development (2006, Dicember), Egyptian Government Enterprise Architecture Framework (EGEAF), Vision \& Scope, [Online]. Available: http://www.egypt.gov.eg/english/documents/download/EGEAF English 05012010141026.zip

[35] Ministry of Communication and Information Technology (2004, March), The Egyptian and Information Society for Government Services Delivery, 2004. [Online]. Available: http://www.egypt.gov.eg/english/documents/download/EISI Gov English paper 05012010134554.zip

[36] M. Pankowska, National frameworks' survey on standardization of e-Government documents and processes for interoperability, Journal of Theoretical and Applied Electronic Commerce Research, vol. 3, no. 3, pp. 64-82, 2008.

[37] M. P. Papazoglou and W.-J. van den Heuvel, Service-Oriented Architectures: Approaches, Technologies and Research Issues, VLDB Journal, vol. 16, no. 3, pp. 289-415, 2007.

[38] M. P. Papazoglou, P. Traverso, S. Dustdar, and F. Leymann, Service-Oriented Computing: State of the Art and Research Challenges, IEEE Computer, vol. 40, no. 11, pp. 38-45, 2007.

[39] T. A. Pardo, A. M. Cresswell, S. S. Dawes, and G. B. Burke, Modeling the Social \& Technical Processes of Interorganizational Information Integration, Proceedings of the $37^{\text {th }}$ Hawaii International Conference on System Sciences, Hawaii, 2004, p.50120.1.

[40] T. A. Pardo and G. K. Tayi, Interorganizational information integration: A key enabler for digital government. Government Information Quarterly, vol. 24, pp. 691-715, 2007.

[41] V. Peristeras, A. Mocan, T. Vitvar, S. Nazir, S.Goudos, and K. Tarabanis, Towards Semantic Web Services for Public Administration based on the Web Service Modeling Ontology (WSMO) and the Governance Enterprise Architecture (GEA), Proceedings EGOV 2006, Krakow, Poland, 2006, pp. 155-162.

[42] V. Peristeras and K. Tarabanis, Governance Enterprise Architecture (GEA): Domain Models for E-Governance, in Proceedings ICEC 2004 (M. Janssen, H. Sol, and R. Wagenaar, Eds.), Lecture Notes in Computer Science, vol. 3166, Springer, Heidelberg, 2004, pp. 471-479.

[43] H. J. Scholl and R. Klischewski, E-Government Integration and Interoperability: Framing the Research Agenda, International Journal of Public Administration, vol. 30, no. 8, pp. 889-920, 2007.

[44] C. Schroth and B. Schmid, A Modular Reference Architecture Framework for Electronic Cross-Organizational Interoperation, in Proceedings EGOV 2008 (M.A. Wimmer, H.J. Scholl, and E. Ferro, Eds.), Lecture Notes in Computer Science, vol. 5184, 2008, pp. 303-314.

[45] S. L. Star and K. Ruhleder, Steps Towards an Ecology of Infrastructure, Information Systems Research, vol. 7, no. 1, pp. 11-34, 1996.

[46] A. M. Sourouni, Paving the Way to eGovernment Transformation: Interoperability Registry Infrastructure Development, in Proceedings EGOV 2008 (M.A. Wimmer, H.J. Scholl, and E. Ferro, Eds.), Lecture Notes in Computer Science, vol. 5184, 2008, pp. 340-351.

[47] E. Tambouris and K. A. Tarabanis, An Overview of DC-based e-Government Metadata Standards and Initiatives. Proceedings of EGOV 2004, Lecture Notes in Computer Science, vol. 3183, 2004, pp. 40-44.

[48] UNDP United Nations Development Program, e-Government Interoperability Guide, Bangkok, Thailand, 2007. Available: http://www.unapcict.org/ecohub/resources/e-government-interoperability-guide

[49] P. Vassilios and T. Konstantinos, Governance enterprise architecture (GEA): domain models for e-governance, in Proceedings of the 6th international conference on Electronic commerce, ACM Press, 2004, pp. 471-479.

[50] X. Wang, T. Vitvar, V. Peristeras, A. Mocan, S.K. Goudos, and K. Tarabanis, WSMO-PA: Formal Specification of Public Administration Service Model on Semantic Web Service Ontology, in Proceedings of the 40th Annual Hawaii International Conference on System Sciences, Big Island, Hawaii, IEEE, 2007. 
[51] P. Weill and M. Broadbent, Leveraging the New Infrastructure: How Market Leaders Capitalize on Information, Boston: Harvard Business School Press, 1998.

[52] P. Weill and J. Ross, A Matrixed Approach to Designing IT Governance, MIT Sloan Management Review, vol. 46, no. 2, pp. 26-34, 2005. 